\title{
The dilemma and Countermeasures of Digital Trade Development in China Under the New Situation
}

\author{
Yiru $\mathrm{Li}^{1}$, Xuejia $\mathrm{Li}^{2}$ and Hongjian $\mathrm{Yu}^{3,}{ }^{*}$ \\ ${ }^{123}$ Alibaba Business School of Hangzhou Normal University, Hangzhou, Zhejiang, China \\ geminilyr@163.com \\ ${ }^{*}$ Corresponding author
}

Keywords: digital trade; cross border e-commerce; new situation.

\begin{abstract}
Digital trade is a technological dispute and a dispute over rules. This paper describes the new situation facing our country, analysis of the difficulties in the development of digital trade: significant differences in infrastructure construction level in China, the rules of digital trade at home and abroad are not uniform, etc. Discussion on countermeasures for developing digital trade: strengthening investment in infrastructure construction, Speed up the formulation of a new international rule system for digital trade. This will contribute to the development and rise of China's digital tra
\end{abstract}

\section{新形势下我国数字贸易发展的困境与对策探讨}

\author{
厉钎汝 ${ }^{1}$, 李ヨ佳 ${ }^{2}$,余红剑 ${ }^{3,{ }^{*}}$ \\ ${ }^{123}$ 杭州师范大学 阿里巴巴商学院, 杭州, 浙江, 中国 \\ geminilyr@163.com \\ “通讯作者
}

关键词: 数字贸易; 跨境电商; 新形势

中文摘要. 数字贸易是技术之争, 也是规则之争。本文阐述了我国面临的新形势, 分析发展 数字贸易面对的困境：国内基础设施建设水平差异显著、国内国际数字贸易规则不统一等, 探讨发展数字贸易的对策：加强基础设施投入建设、加快制定新的数字贸易国际规则体系， 禆益我国数字贸易的发展和崛起。

\section{1. 引言}

我们现在正在进入数字时代。2018年的研究表明，中国数字经济规模达到 31.3 万亿元， 占GDP的 $34.8 \%$, 还在不断释放着对数据消费, 数字贸易、数字经济投资等方面的增长性需 求。其中江苏, 广东和浙江数字经济的规模约占全国的三分之一, 数字贸易的发展前景十分 广阔。

\section{2. 数字贸易概述}

依托于数字经济的发展, 数字贸易逐渐兴起, 以数字技术作为数字贸易发展的基石, 电 子商务是其早期的主要表现形式。数字贸易是全球化与数字经济交融发展到一定时期的结果, 同时也可以将其视为一种跨境电子商务的数字化延伸。从本质上来说，数字贸易与跨境电子 
商务并没有区别, 两者同属一脉, 都具有很多相同特点和属性。但是在现实应用中，跨境电 子商务通常主要指基于互联网而进行的跨境货物贸易及其相关的服务, 跨境电子商务的核心 仍然在于货物的流动; 而数字贸易的核心则在于数据的流动, 后者更侧重于数字化内容的交 付以及服务的跨境流动。

\section{3. 国内国外新形势}

\section{1 中美贸易摩擦与美国贸易保护主义}

随着中美贸易关系的迅速发展, 近年来有关双边贸易的纠纷摩擦也呈现日益加剧的趋势。 我国是发展中国家，市场经济制度还在趋于完善的过程中，政治制度、传统文化和美国这个 西方国家都存在比较大的差异, 在经济全球化的背景下, 贸易摩擦在所难免。中美两国关于 经济利益的纠纷、现在美国盛行的贸易保护主义做法以及美国对中国的战略性抵制措施等都 是中美双方贸易纠纷日渐增加的主要原因。贸易摩擦对于中美贸易关系的发展带来的影响是 负面的。

\section{2 第五代移动通信技术 (5G)}

“万物互联”--这个以5G为代表的新时代已经正式开启，而这也是加速了我国探索数字贸 易全球新规则的进程。数字贸易作为现在以及未来很长时间内主要的发展方向, $5 \mathrm{G}$ 的落地商 用也给数字贸易过程带来了更多挑战与困难, 速度暴增, 数据暴涨, 都对数据监管提出更高 标准的需求。高数据监管的科学性和透明度都是当务之急, 既要正式跨境数据流动监管对于 保护隐私安全的重要性, 又要在防范风险的前提下, 对数据进行更科学的分类监管, 快且稳 地放松对商业数据的跨境流动限制, 并强化企业在个人隐私和安全保护上的责任和义务。

\subsection{AI、AR、区块链等新兴技术}

无论是AI人工智能的商品识别还是增强现实像AR的智能客服, 在新贸易时代这些新的科 技手段都在和产业深度地融合，极大地提升数字贸易和新贸易在这里的效率。在制造业中， 随着数字技术的发展, 制造业正变得越来越数字化, 智能化和网络化。这为传统商业形式向 数字商业的过渡奠定了坚实的基础。

区块链概念是中本聪于 2008 年首次提出的，区块链技术找到了所有贸易参与者都认可的 共识: 信任。物流、供应链等一系列贸易环节都建立在信任之上, 区块链用技术实现信任具 像化并进行积累、流通。区块链不仅是一项技术，更是一种经济体制与合作的新途径。

数字经济的井喷式增长为跨境数字贸易的发展奠定了牢固的根基, 为数字贸易带来了全 新的发展机遇, 不过解决在传统模式下困扰跨境贸易发展的信任问题仍然是推动跨境数字贸 易发展的前提条件, 借助分布式数据存储、点对点传输等计算机技术的应用, 跨境数字贸易 通过区块链开启了通往新世界的大门。

\section{4 电子商务法的颁布实施}

《电商法》强化电商平台经营者知识产权保护制度。根据国际发展趋势颁布的《电子商 务法》, 专门旨在加强平台经济中的知识产权保护。《电子商务法》确立了平台运营商对知 识产权的责任这一事实, 它可以有效地打击电子商务领域的盗版行为。中国要在数字贸易规 则领域与国际接轨。《电子商务法》旨在平衡各方利益和权利, 提升这一经济领域的竞争力。 中国应确保拥有稳健高效的数据管理框架, 采取积极措施。通过贸易便利化措施, 提高低价 值小型包裹的清关和投递效率，减少一些流程和关税，进一步促进跨境交易。 


\section{5 “一带一路”战略}

“一带一路”沿线的 64 个国家约占世界人口的 $43 \%$, 约占世界GDP的 $16 \%$, 贸易总额占世 界贸易总额的 $22 \%$ 。“一带一路”沿线国家人口基础庞大, 经济欠发达, 随着“一带一路”合作 的加深, 不可避免地会增加沿线国家重大的经贸合作机会。跨境电子商务在世界出口贸易中 的份额为 $13 \%$ 。数字贸易已成为刺激沿线国家开展贸易和经济合作的重要工具, 并且在沿线 国家中存在巨大的发展空间。随着中国的“互联网+”战略和“一带一路”, “网上丝绸之路”战略 的深入发展，数字贸易将拥有前所未有的发展机遇。

\section{4. 我国数字贸易发展的困境}

\section{1 基础设备建设水平差异大}

其实早在2013年，我国就提出了“宽带中国”战略，提出了“城市光纤到楼入户、农村宽带 进乡入村”等战略目标和推进时间表。但是, 从实际执行效果来看, 我国电信基础设施建设仍 有一定的提升空间, 设施建设仍需加强。具体表现在, 城市宽带的接入速度还不高, 广大的 农村地区, 尤其是老少边穷地区, 宽带网络的普及率亟待提升, 即便是在城市, 移动互联网 的速度、稳定性及信号的覆盖度都还存在提升空间。

此外，我国虽然放宽了市场准入，但考虑到电信基础设施巨大的前期投入，民营资本进 入的广度和深度都还不高, 这在很大程度上导致了国有企业的垄断行为, 而由垄断导致的高 收费也一直广为大家所诟病。与此同时, 我国在数据全球化流动方面与发达国家差距明显, 数据全球性连接方面仅居于第38位, 远远落后于美国、德国、英国、法国、日本等。

\section{2 各国在数字贸易监管规则上未完全统一}

全球贸易大国都正在努力塑造新兴经济和数字贸易的未来。美国在数字贸易监管领域高 举自由主义大旗, 旨在消除数字贸易壁垒。这种自由主义模式强调跨境自由流动数据的价值, 数据本地化的成本, 以及避免不必要的安全措施等优先事项。另一种声音则是以欧盟为代表 的保守派, 强调高度重视个人信息保护, 认为数据自由流动不能凌驾于个人信息保护之上。 欧盟认为数字流动的原则可以服从于国际协议，但决不更改国内法律。

相较之下, 我国在数字贸易的监管方面较为严格和全面, 尤其在对数字信息跨境流动方 面, 建立了“大防火墙制度”。通过实施《网络安全法》, 我国来规范网络安全与数字信息的 跨境流动。该法律强制性对物理数据存储、强制执行数据保留条例, 同时强调在网络安装之 前对设备进行强制性安全检查。

互联网环境下的贸易与数据流动密切相关, 因为数据流动的自由度与贸易的自由度和简 化程度有关, 并且对数据自由流动的限制可能是由于不合理的贸易壁垒或者是由于国家安全 要求所致。我国如何在确保安全的同时促进开放是数字贸易管理规则的主要困难之一。

\section{3 知识产权保护机制的缺乏}

目前, 许多跨境电商出口企业对于知识产权的概念较为薄弱, 对于国际知识产权法更是 缺乏了解。有些企业更是为追求短期的利益, 销售假冒伪劣产品和盗版仿制品。由于欧洲和 美国市场都十分关注重知识产权问题, 中国的跨境电子商务出口公司很容易受到侵犯, 会受 到下架产品、缴纳罚款, 更甚者面临法律起诉的风险。

与此同时, 中国很多独立自主品牌都缺乏对知识产权保护的措施, 无法及时申请海外产 品商标和专利, 而让其竞争对手钻了空子, 从而对跨境电子商务企业造成巨大的损失。 


\section{5. 我国数字贸易发展对策建议}

\section{1 积极参加数字贸易国际规则的制定}

当前, 全球数字贸易规则正在逐步成型的过程中，以美国、欧盟为首的发达国家纷纷抢 占相关规则制定的主导权。为此, 我国也需要提早进行部署, 以防在新规则的制定中处于被 动地位。一方面, 我国可以借助国际组织平台积极参与相关议题的磋商, 在新规则的制定中 加强自己的话语权。另一方面，我国还可以通过亚太自由贸易区谈判（FTAAP）或者其他一 些双边自由贸易谈判来尝试构建符合我国利益的数据本地化规则。我国还可以利用“一带一 路”政策的契机，与相关国家开展数字贸易规则的讨论，寻求与他国建立数据共享机制。

\section{2 加强基础设施领域建设}

具有显著“乘数效应”的基础设施建设在促民生、拉内需、支撑其他上层产业发展方面具 有明显的作用。完善基础设施网络是新时代的必然要求宽带网络是构建国家数字贸易蓬勃发 展的根基, 也是数字贸易蓬勃发展的基础性技术。宽带网络的速度、普及率和费用, 直接决 定着数字贸易发展的广度和深度。要把数字基础设施建设的重要性上升到更高的层面。将数 字基础设施建设架构的重要性提升到更高的水平，同时也要加快制定交流数字证书、电子签 名和电子认证有关联的信息和政策，促进数字证书和电子签名互认。要将老少边贫地区作为 攻坚重点, 扩大基础设施公共服务的供给范围, 围绕通路、通水、通电、通互联网提高公共 服务共建能力和共享水平。同时要稳步推进城市网络的速度升级，对农村推广宽带普及的重 要性。同时, 均衡城乡公共资源配置, 推动城市公共服务资源向农村延伸, 削弱数字基础设 施的市场准入门槛，发挥国有企业在基础设施投入方面的引领作用。

\section{3 引导企业加强自身自律性}

国家应当采取相关措施, 引导从事数字贸易的相关企业加强自律性，在注意数据来源合 法性的同时，防止数据的跨境转移可能会给国家安全和个人隐私造成的损害。此外，还需要 提醒从事数字贸易的企业经常关注国外的相关规定。

\section{4 持续深入推进“一带一路”建设}

金融创新的方向必须要与科技相结合:“无科技不金融”已经成为了金融等其他行业的一 致共识。金融机构必须充分利用科技的力量，才能改善服务实体经济的能力。只有当我们专 注于服务与推动实体经济, 在紧密参与实体经济发展中并严格遵循国家重大战略大方向时, 我们才能实现可持续发展, 提振真正的竞争力。

\section{References}

[1] Li Zhiqiang, Wang Yaping. The Status Quo and Development Trend of Cross-border E-commerce Business Model in China[J]. Economic Research Guide, 2019(24): 162-163.

[2] Tang Wei. New developments and new features of international digital trade regulation [J]. International Economic Cooperation, 2019 (01): 74-79.

[3] Li Baixing. Opportunities and challenges of cross-border e-commerce development in China under the new situation [J]. Wireless Internet Technology, 2018, 15 (24): 124-126.

[4] Yin Haozhen, Wu Kexin. Analysis of the Impact of E-commerce Law on China's Cross-border E-commerce[J]. Economic and Trade Practice, 2018(24): 186.

[5] "China's financial development strategy in the new era" [J]. Finance and Trade, 2018, 39 (10): 162.

[6] Dong Xiaojun, Guo Beibei. The Status Quo, Causes and Countermeasures of Sino-US Trade Friction[J].Industrial Innovation Research,2018(07):1-5. 